\title{
Innate recognition of pheromone and food odors in moths: a common mechanism in the antennal lobe?
}

\section{Joshua P. Martin* and John G. Hildebrand}

Department of Neuroscience, University of Arizona, Tucson, AZ, USA

\section{Edited by:}

Kathleen A. French,

University of California San Diego, USA

Reviewed by:

Charles E. Linn

Cornell University, USA

Christoph Kleineidam,

University of Konstanz, Germany

*Correspondence:

Joshua P. Martin,

Department of Neuroscience,

University of Arizona, Gould-Simpson

Room. 611, 1040 E 4th Street, Tucson,

AZ 85716, USA.

e-mail:jpmartin@email.arizona.edu
The survival of an animal often depends on an innate response to a particular sensory stimulus. For an adult male moth, two categories of odors are innately attractive: pheromone released by conspecific females, and the floral scents of certain, often co-evolved, plants. These odors consist of multiple volatiles in characteristic mixtures. Here, we review evidence that both categories of odors are processed as sensory objects, and we suggest a mechanism in the primary olfactory center, the antennal lobe (AL), that encodes the configuration of these mixtures and may underlie recognition of innately attractive odors. In the pheromone system, mixtures of two or three volatiles elicit upwind flight. Peripheral changes are associated with behavioral changes in speciation, and suggest the existence of a pattern recognition mechanism for pheromone mixtures in the AL. Moths are similarly innately attracted to certain floral scents. Though floral scents consist of multiple volatiles that activate a broad array of receptor neurons, only a smaller subset, numerically comparable to pheromone mixtures, is necessary and sufficient to elicit behavior. Both pheromone and floral scent mixtures that produce attraction to the odor source elicit synchronous action potentials in particular populations of output (projection) neurons (PNs) in the AL. We propose a model in which the synchronous output of a population of PNs encodes the configuration of an innately attractive mixture, and thus comprises an innate mechanism for releasing odor-tracking behavior. The particular example of olfaction in moths may inform the general question of how sensory objects trigger innate responses.

Keywords: floral scent, moths, neuroethology, olfaction, pheromone, sensory coding, sensory object, synchrony

\section{INTRODUCTION}

The olfaction-based behavior of an animal is governed by a tradeoff: focusing on a narrow range of innately attractive odors efficiently guides the animal to mates and food sources that are most likely to be rewarding, while a flexible olfactory system that explores new odors and associates new rewards with them is resistant to changes in the availability of any one source (Waser et al., 1996; Chittka et al., 1999; Memmott et al., 2004). For a moth emerging from its pupal stage, with only a few days to a few weeks of adult life ahead of it to eat and mate, coming prepared with pre-programmed search images for the mates and night-blooming flowers they are likely to encounter, along with a capacity to learn new sources of food, could be highly valuable.

Most moths take flight at night, when the utility of visual signals is at a nadir. As nocturnal flyers, moths rely mainly on olfaction (Balkenius et al., 2006). Chemical cues released into the air can guide moths to sources of food or mates over long distances (Wall and Perry, 1987), and are behaviorally active at remarkably low concentrations. For example, only a few molecules of pheromone or plant odors can trigger increased heart rates in moths (Angioy et al., 2003).

Here, we review neuroethological findings about selected, innate mate-seeking and feeding behaviors of moths and ask if there is a common operating principle for a neural substrate underlying recognition of an innately attractive odor. We propose that for both sex pheromone and food odors, the circuitry of the antennal lobe (AL) produces a pattern of coordinated output for attractive odors from either category. Our review is not exhaustive but intends to make a case for the existence of such a mechanism in many, if not all moths.

\section{SPECIES RECOGNITION BY PHEROMONE BLENDS}

Animals are, by necessity, specialists when searching for mates. The consequences of pursuing a mate from a related but reproductively isolated species are dire for animals that expend much energy in long-distance flights (Bartholomew and Casey, 1978). Moths have evolved a system of sex-pheromonal communication between calling females (senders) and conspecific males (receivers), incorporating the production of a suite of chemicals by females. These consist, for the most part, of aliphatic acetates, alcohols, and/or aldehydes with hydrocarbon chains 10-22 carbon atoms in length and often with one or more double bonds (Byers, 2005). This chemical alphabet allows for numerous unique molecules to be used as components of signals. Considering only the possible variations of the most commonly used molecules, Byers (2005) estimates there are over 100,000 possible pheromonal volatiles. Here, we review the evidence from the peripheral reception of pheromone odors in moths that suggests the existence of a template in the AL for the recognition of complex odors. We particularly emphasize how changes in behavioral selectivity that follow changes in the periphery can be understood as an alteration of the input to a pre-existing AL template. In the proceeding sections, we will describe the evidence for the nature of this template. 
The use of fine variations on a single molecular theme requires a male receiver to have sufficiently specific receptors to accept certain variants and reject all others. The antennae of male moths carry olfactory organules - olfactory sensillacontaining olfactory receptor cells (ORCs) that respond with such specificity. For instance, ORCs of one phenotype present in a particular species respond specifically to a 14-carbon acetate with a double bond at carbon 11 in the cis configuration, and not to the trans isomer (Wanner et al., 2010). Pheromone-binding proteins in the lymph that bathes ORCs in antennal sensilla can increase the specificity of receptor responses further (GrosseWilde et al., 2006).

Most moth species employ multi-component pheromone mixtures instead of monomolecular signals (Byers, 2006). Two factors likely necessitate this level of complexity. First, genera with closely related, sympatric species often have sex pheromones with at least one component in common (Byers, 2006). Second, there are limits to the specificity of an ORC, and there are many examples of ORCs in one species that respond to pheromone components used by other species (Grant et al., 1989; Lofstedt, 1990; Berg et al., 1995; Domingue et al., 2007b, 2008). This may reflect an upper limit to the ability of a receptor to reject molecules that are highly similar to the preferred ligand and would lead to ambiguity between a non-preferred ligand at high concentration and a preferred ligand at low concentration.

Related moth species also may use pheromone mixtures with identical components, but in ratios specific to each species (Baker, 2008). A pattern is emerging that describes a large number of moth pheromone mixtures: a "major" component (providing a majority of molecules in the blend) and one or more "minor" components (often present at a much lower concentration but nevertheless required to elicit behavior in a recipient moth). Moreover, attraction to a pheromone blend may be inhibited by "antagonistic" compounds in the pheromone mixtures of other species (Baker and Heath, 2004). Species recognition thus requires a form of rudimentary pattern recognition, dependent on the arrangement of features in a complex stimulus, in the olfactory system of a male moth (Baker, 2008).

Clues about the nature of the pattern-recognition mechanism come from several observations of individual moths for which the parameters of an acceptable pattern have shifted. Accompanying these behavioral shifts are some revealing changes in the responses of the ORCs to pheromone blends typically rejected by "normal" moths. In a laboratory colony of Trichoplusia ni, a strain spontaneously arose in which females emit roughly equivalent amounts of the major and minor pheromone components instead of the typical 1:100 ratio (Haynes and Hunt, 1990). Over several generations, males emerged that were attracted to the mutant blend (Liu and Haynes, 1994). In normal males, the ratio between the major and minor components is reflected in the ratio between responses of the corresponding "major" and "minor" ORCs (Domingue et al., 2009). In the males evolved to accept the mutant blend, the response of the minor ORC was decreased, such that the nearly equal ratio between components still produced an unequal ratio of responses between the types of ORCs (Domingue et al., 2009). The ratio of ORC responses of evolved males to the mutant blend was thus similar to that of normal males to the normal blend.
Another case study provides an additional clue. In males of the species Ostrinia nubilalis, ORCs for the major and minor components of the conspecific sex-pheromone blend also respond weakly to the pheromone components of a related species, O. furnacalis, which differ only in the position of the double bond (Domingue et al., 2007a). This illustrates the utility of encoding schemes that depend on more than just the presence of a particular pheromone molecule (i.e. "labeled-line" coding), as a high concentration of O. furnacalis components would be indistinguishable from a low concentration of conspecific components. In contrast, the relative activity of neurons responding to an odor is typically consistent across concentrations, and is hypothesized to underlie "concentration invariant" encoding of odor identity (Cleland et al., 2007; Uchida and Mainen, 2007; Asahina et al., 2009).

Despite the incomplete specificity of their ORCs, only rare $O$. nubilalis males are attracted to the $O$. furnacalis pheromone, in which the major and minor components are present in an approximately 1:1 ratio (Linn et al., 2003). Major and minor ORCs in both normal and rare males have similar sensitivity to the major and minor components of the conspecific pheromone and thus produce a ratio of responses congruent with the 99:1 ratio of components in an attractive blend (Domingue et al., 2007a). Responses to the heterospecific $O$. furnacalis components in normal males also reflect the 1:1 ratio of components in the pheromone of that species, allowing the animal to discriminate between the blends. In the rare males, the response of the minor ORC to the heterospecific pheromone component is greatly diminished, producing a response closer to 99:1 when presented with a 1:1 stimulus and thus facilitating a behavioral response to the odor (Domingue et al., 2007a).

These studies and others on peripheral changes in pheromone processing suggest the existence of an internal template for the ratio of components in a conspecific pheromone blend (Baker, 2008). In both examples, sensitivity in the periphery changed, producing a response to a new mixture that had a ratio of major and minor ORC activation similar to that observed in response to the conspecific blend. Where might the template for such a pattern be located? The axons of pheromone-responsive ORCs terminate in the AL in a set of large, male-specific glomeruli called the macroglomerular complex (MGC) (Matsumoto and Hildebrand, 1981). An additional clue from the periphery suggests that the template exists there, at least in part.

The species $O$. nubilalis comprises two strains, differing only in the ratio of components produced by females and attractive to males: an "E-strain" and a "Z-strain," named for the isomer of the major pheromone component (Carde et al., 1978; Anglade and Stockel, 1984). The major component for one strain is the minor component for the other, and vice versa. In both strains, major ORCs terminate in the larger of two glomeruli in the MGC, and minor ORCs in the smaller (Karpati et al., 2008).

This arrangement is also found in male moths of the subfamily Heliothinae. Evidence from both the input ORCs (Berg et al., 1998, 2005; Galizia et al., 2000; Lee et al., 2006a,b) and output projection neurons (PNs) (Christensen et al., 1995b; Vickers and Christensen, 1998, 2003; Vickers et al., 1998) in the MGC demonstrates that the major component, shared across all four species studied in detail, is processed in the largest glomerulus, called the cumulus. One or more minor components, and in some species a component 
that antagonizes behavior, are processed in smaller glomeruli surrounding the cumulus. The proximity of these glomeruli, and the conserved functional relationship across species, suggests that they are incorporated into a conserved network at the level of the AL that performs the initial processing necessary for species-specific pattern recognition.

The network architecture of the AL consists primarily of inhibitory, GABAergic neurons that have arborizations throughout the AL (Anton and Homberg, 1999). These local interneurons (LNs) connect the glomeruli of the MGC and facilitate reciprocal inhibition between them (Waldrop et al., 1987; Christensen et al., 1993; Christensen and Hildebrand, 1997; Lei et al., 2002). This is best established in Manduca sexta, a species for which two pheromone components in a 1:2 ratio are necessary and sufficient for attraction of male moths to the source of the stimulus (Tumlinson et al., 1989). Stimulation with one component activates ORCs projecting to one glomerulus (Kaissling et al., 1989; Christensen et al., 1995a), PNs arborizing in that glomerulus (Christensen and Hildebrand, 1987; Hansson et al., 1991), and LNs arborizing in both glomeruli (Christensen et al., 1993), and inhibits the background firing of PNs in the MGC glomerulus activated by the other component (Christensen and Hildebrand, 1997; Lei et al., 2002).

Information about the presence, and potentially the quantity, of each component is thus transmitted between glomeruli. The effect of these inhibitory inputs is not to reduce the output carried by PNs in response to a blend of both pheromone components, but rather to increase the coordination, or synchrony, of their action potentials (Lei et al., 2002). Synchrony between spikes produced by PNs arborizing in the same glomerulus, but not by $\mathrm{PNs}$ arborizing in neighboring glomeruli, increased in response to the blend. This result is similar to what is seen in the Drosophila AL, though in that system the effect does not rely on interglomerular inhibition (Kazama and Wilson, 2009). In contrast, the degree of synchrony between moth MGC PNs is correlated with the strength of inhibition they receive from the neighboring glomerulus (Lei et al., 2002). Synchrony provides an additional coding dimension (Singer, 1999; Biederlack et al., 2006) in the output of the MGC, such that the presence and intensity of each pheromone component can be encoded by the rate of firing of individual $\mathrm{PNs}$, while the presence of both components together in a mixture is encoded in the coordination of firing of PNs. Conceptually, synchronous firing of two neurons can be thought of as a new, active, virtual neuron that is more effective in driving responses down-stream and more selective to behaviorally relevant mixtures than either of the neurons that produce it (Ghose et al., 1994).

Synchrony, typically shaped by inhibitory networks, has been investigated and debated for years as a possible mechanism for "binding" the features of a complex stimulus to produce a unitary representation (Engel et al., 1992; Engel and Singer, 2001; Lestienne, 2001; Robertson, 2003; Averbeck and Lee, 2004). We propose that the inhibitory network linking MGC glomeruli provides the mechanism by which the features of an encountered pheromone mixture are compared to an internal template for the conspecific mixture, and the output of synchronous spikes encodes a blend that fits this template.

\section{INNATELY ATTRACTIVE FLORAL ODORS AND SYNCHRONOUS CODES}

Beyond the enlarged glomeruli of the MGC in the AL of a male moth lie a larger number of "ordinary" glomeruli, in a region called the main AL (Anton and Homberg, 1999). These glomeruli process sensory input about volatiles from flowers (sources of nectar) and foliage of host plants (on which females lay eggs) (Galizia et al., 2000). Although more is known about the pheromone-processing pathways of the MGC, emerging evidence suggests that the processing of innately attractive, complex odors in both regions of the AL share fundamental traits.

While the MGC and main AL mediate different olfactory behaviors, there are many similarities between the two compartments (Christensen and Hildebrand, 2002). However, evidence from calcium-imaging (Galizia et al., 2000; Carlsson et al., 2002; Hansson et al., 2003) indicates that aggregate activity (calcium activity representing input, local circuitry, and output) in response to pheromone and plant odors is isolated to the MGC and main AL, respectively. Also, intracellular recordings (Reisenman et al., 2008) suggest that while the main AL receives significant inhibition originating from the MGC, the MGC receives no inhibition from some glomeruli, and only receives inhibition when the AL is activated by high concentrations of floral odors. Thus, the two are functionally separate compartments that may interact when the animal encounters both pheromone and floral odors. A similar arrangement is suggested by the anatomical arrangement of glomeruli in the antennal lobe of Drosophila, where classes of local neurons arborize in glomeruli across the AL, but avoid those involved in processing putative pheromone odors (Wilson and Laurent, 2005; Chou et al., 2010).

While pheromonal stimuli are the gold standard for innate, olfaction-based attraction and discrimination, naive moths are also innately attracted to the scent of certain flowers in preference to others (Plepys et al., 2002; Raguso and Willis, 2002; Riffell et al., 2008). The co-evolution of flowers and their moth pollinators is most remarkable in flowers pollinated by hawk moths (Grant and Grant, 1983). Those flowers have long, slender nectaries accessible to the moth's long proboscis (Darwin, 1862; Nilsson, 1988), large white, reflective surfaces (Raguso et al., 2003), and a strong, sweet fragrance. M. sexta moths exhibit innate attraction to the scent of the flowers of Datura wrightii, which is seasonally abundant in part of their range (Raguso and Willis, 2002; Riffell et al., 2008). Although this flower releases a mixture of volatiles consisting of more than 65 components (Raguso et al., 2003), neurons in the AL respond robustly to only nine of those compounds (Riffell et al., 2009a), and a mixture of just three of these volatiles is sufficient to attract naive moths (Riffell et al., 2009b). Thus the initially daunting complexity of a floral scent may be reduced in the olfactory processing of an animal to something more closely approximating that of a pheromone blend. A behavioral focus on a reduced subset of volatiles in a complex mixture also has been observed recently in honey bees (Reinhard et al., 2010).

Owing perhaps in part to the more broadly tuned ORCs that innervate the main AL (Wang et al., 2003; Hallem and Carlson, 2006), mixtures of plant volatiles activate a significantly larger number of glomeruli (Lei et al., 2004; Skiri et al., 2004; Pinero et al., 2008) than do pheromones. Nevertheless, simultaneous recordings from neurons across the AL show that in response to an innately attractive floral scent, a pattern of firing synchrony emerges (Riffell et al., 2009b). This 
pattern is conserved in response to attractive blends with reduced numbers of components and is distinct from patterns generated by non-attractive mixtures and single components (Riffell et al., 2009b). Attractive odors also generate a distinctive pattern of firing rates across the ensemble of neurons. However, by using a shift-predictor measure of synchrony (Perkel et al., 1967), the authors ensure that the measures of synchrony and firing rate are independent. Thus both firing rate and synchrony may independently encode the presence of attractive floral scents (Riffell et al., 2009b). Synchrony, but not firing rate, is maintained across a range of concentrations that were detectable and attractive to the animal, providing a neural correlate of "concentration invariance” (Riffell et al., 2009a). An ensemble of synchronously responding neurons, innervating a larger number of glomeruli, thus is involved in encoding an innately attractive floral odor in a manner similar to that observed with sex pheromone in the MGC.

A fairly superficial analysis of the output of the AL thus has suggested that pheromonal and plant-odor processing share common mechanisms, wherein innately attractive mixtures of volatiles activate innate templates in the AL network, producing synchronous output among PNs. Particular patterns of synchrony are correlated with innate olfactory behaviors, and are absent in response to stimuli that are not attractive (Riffell et al., 2009b). Definitive proof of this hypothesis will require a pharmacological or genetic manipulation that disrupts synchrony in response to a normally attractive odor, and consequently behavior.

As local neurons arborize similarly among glomeruli in the main AL and in the MGC (Hoskins et al., 1986), it is likely that similar networks of reciprocal inhibition are involved in both regions of the AL. Indeed, data from studies of inhibition between glomeruli suggest a possible mechanism. For a small number of glomeruli that have been tested, interglomerular inhibition is not symmetrical (Reisenman et al., 2008). Data from calcium-imaging studies of honey bees and Drosophila melanogaster suggest that the strength of inhibitory connection is specific to each pair of glomeruli (Sachse and Galizia, 2002, 2003; Linster et al., 2005; Silbering and Galizia, 2007). A network of inhibitory connections, set according to some genetic program, could transform ORC inputs responding to a range of innately attractive odors into particular patterns of synchronized PN output, to be read at higher levels of processing.

Like honey bees, moths can learn readily to associate odors with rewards by both classical conditioning (Hartlieb, 1996; Fan et al., 1997; Daly and Smith, 2000) and in more naturalistic protocols related to foraging (Cunningham et al., 2004; Riffell et al., 2008). Evidence for learning in the wild also exists, as moths are found to feed from flowers to which they are not innately attracted when the preferred, innately attractive flower is scarce (Riffell et al., 2008). Simultaneous recordings from moths learning to associate an odor with a sucrose-solution reward reveal that neurons are recruited into the ensemble encoding the rewarded odor (Daly et al., 2004). Further research will clarify whether these changes make the representation of a learned odor more similar to an innately attractive odor.

\section{CONCLUSIONS}

We have reviewed evidence that innate odor attraction in moths is mediated by mechanisms in the AL that recognize and respond to the configuration of a complex odor. In both the specialized, pheromone-processing MGC and the more generalized, plant- odor-processing main AL, innately attractive odors produce patterns of synchronous output. We have presented the available evidence that synchrony is the feature of AL output that encodes the innate salience of an odor. The mechanism underlying this firing synchrony is unknown, but future investigations can benefit from comparisons between pheromonal- and plant-odor-coding networks. It is important to note that this function of the AL does not preclude other functions, such as lateral inhibition, decorrelation, and gain control (Wilson and Mainen, 2006), which may occur in tandem. Nor does it invert the tendency to attribute too little to the AL by attributing too much, as there are certainly more processes in higher olfactory centers linking stimulus and behavior.

Our model of processing of innately attractive odors in the AL is depicted in Figure 1. Both sex pheromone and plant odors consist of mixtures of components present in various proportions (grayscale and colored dots in Figures 1A,E, respectively). A moth apparently requires only a subset of these volatiles to initiate innate behaviors. In the male-specific, pheromone-processing subsystem, each of multiple highly specific receptors (represented by various shades of gray in Figure 1B) responds to only one of the components of the mixture. In contrast, receptors in the plant-odor-processing subsystem are variously selective (indicated by the color of the ORN in Figure 1F) and sensitive (indicated by the saturation of the color) to one or more components of the plant odor. Plant odors thus are represented across a population of ORCs. A map of the connectivity of ORCs to their main glomerular targets in the AL is not yet available in detail. Pheromone-responsive ORCs provide synaptic input to the large glomeruli of the MGC (Figure 1C), where LNs (represented by blue arrows) mediate reciprocal inhibition between glomeruli. Although most moths have 3-4 MGC glomeruli, we currently have evidence for only the interaction of two MGC glomeruli in encoding a pheromone mixture.

In response to stimulation with the pheromonal mixture, $\mathrm{PNs}$ in each MGC glomerulus produce more synchronous spikes (red raster lines superimposed on gray and black arrows in 1C) with other PNs in the same glomerulus. Similarly, an innately attractive odor produces a pattern of synchrony in the main AL (indicated by black lines in Figure 1G). The output of each subsystem (green arrows in Figures 1D,H) that encodes the odor is thus a pattern of synchrony between PNs in the same glomerulus for pheromone odors (Figure 1D) and across multiple, heterogeneous PNs in the main AL (Figure 1H).

The particular features of this scheme, i.e. the importance of the configuration of a complex stimulus and encoding of higher dimensions of a stimulus via synchrony, parallel those uncovered in other work (Meister, 1996; Dan et al., 1998; Krahe et al., 2002; Cleland et al., 2007; Uchida and Mainen, 2007; Marsat et al., 2009; Avargues-Weber et al., 2010) and stems naturally from the observation that sensory systems are tuned, at various levels, to stimuli that are important for survival (Atick, 1992; Dusenberry, 1992). The fundamental similarities between olfactory information processing and storage in brains separated by hundreds of millions of years of evolution are becoming clearer and more numerous over time (Hildebrand and Shepherd, 1997; Davis, 2004; Ache and Young, 2005; Wilson and Mainen, 2006; Touhara and Vosshall, 2009). It seems likely that much of what is learned from moths will find parallels in other animals. 
A

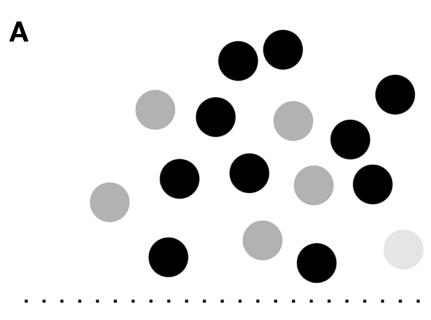

B

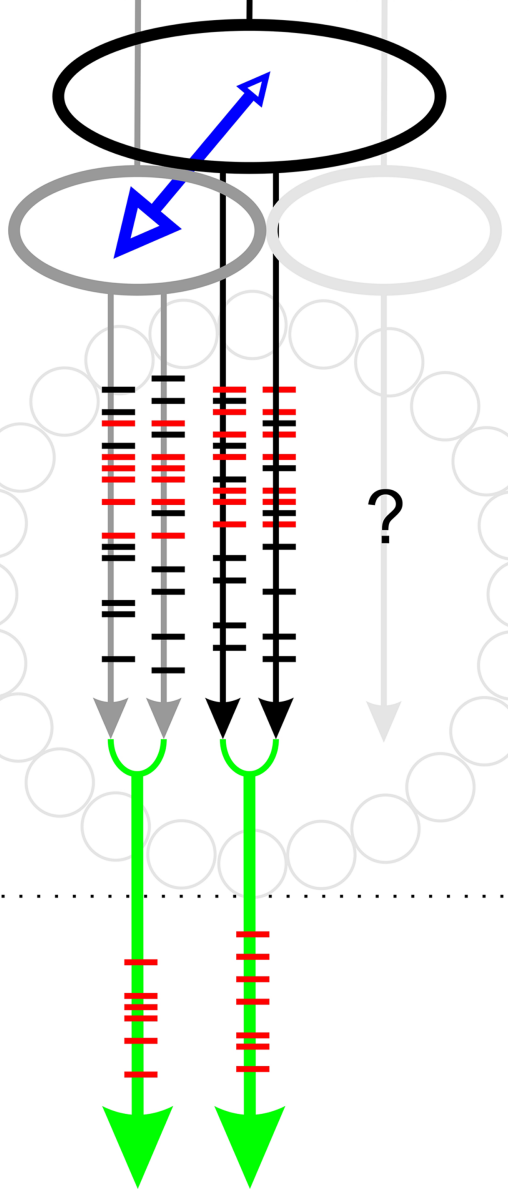

FIGURE 1 | Processing of innately attractive odor mixtures in the sexpheromonal (A-D) and plant-odor (E-H) subsystems of the moth's antennal lobe. (A) Sex pheromones of moths typically comprise a "major" component (black circles) and one or more "minor" components (gray and light gray circles). (B) Pheromonal ORCs respond specifically to one of the components of the pheromone (colors corresponding to component colors in A). (C) Pheromonal ORCs synapse in glomeruli (large ovals). Glomeruli are connected by LNs (blue arrows) that mediate reciprocal inhibition. The output of PNs in each glomerulus (gray and black lines with superimposed spike rasters) in response to the

\section{ACKNOWLEDGMENTS}

The authors gratefully acknowledge the financial support of $\mathrm{NIH}$ grant DC-02751 (to J. G. Hildebrand) and NIH NRSA fellowship pheromone includes a high proportion of synchronized spikes (red rasters). (D) Trains of synchronous spikes comprise the mixture-specific output of the MGC. (E) Plant odors typically include a large number of volatiles (colored circles), of which only a few may be necessary to elicit behavior. (F) Multiple ORCs respond to plant volatiles to varying degrees (colors represent specificity to correspondingly colored component from $\mathrm{E}$, saturation of color represents sensitivity). (G) Stimulation with an innately attractive odor produces a pattern of synchrony (black lines) across the AL. $\mathbf{( H )}$ The mixture-specific output of the main $A L$ is characterized by a pattern of synchronized firing of PNs from across the AL.

DC97222 (to J. P. Martin). We also thank J.A. Riffell, H. Lei, A.M. Dacks, and A. Beyerlein for extremely helpful comments and discussion of the ideas in this review. 


\section{REFERENCES}

Ache, B. W., and Young, J. M. (2005). Olfaction: diverse species, conserved principles. Neuron 48, 417-430.

Angioy,A.M., Desogus, A., Barbarossa, I. T., Anderson, P., and Hansson, B.S. (2003). Extreme sensitivity in an olfactory system. Chem. Senses 28, 279-284.

Anglade, P., and Stockel, J. (1984). Intraspecific sex pheromone variability in the European corn borer, Ostrinia nubilalis Hbn. (Lepidoptea, Pyralidae). Agronomie 4, 183-187.

Anton, S., and Homberg, U. (1999). "Antennal lobe structure," in Insect Olfaction, ed. B. S. Hansson (Heidelberg: Springer), 98-125.

Asahina, K., Louis, M., Piccinotti, S., and Vosshall, L. B. (2009). A circuit supporting concentration-invariant odor perception in Drosophila. J. Biol. 8, 9.

Atick, J. J. (1992). Could informationtheory provide an ecological theory of sensory processing. Network: Comput. Neural Syst. 3, 213-251.

Avargues-Weber, A., Portelli, G., Benard, J., Dyer, A., and Giurfa, M. (2010). Configural processing enables discrimination and categorization of face-like stimuli in honeybees. J. Exp. Biol. 213, 593-601.

Averbeck, B. B., and Lee, D. (2004). Coding and transmission of information by neural ensembles. Trends Neurosci. 27, 225-230.

Baker, T. C. (2008). Balanced olfactory antagonism as a concept for understanding evolutionary shifts in moth sex pheromone blends. J. Chem. Ecol. 34, 971-981.

Baker, T. C., and Heath, J. J. (2004). "Pheromones-function and use in insect control," In Molecular Insect Science, eds L. I. Gilbert, K. Iatro, and S. S. Gill (The Netherlands: Elsevier), 407-460.

Balkenius, A., Rosen, W., and Kelber, A. (2006). The relative importance of olfaction and vision in a diurnal and a nocturnal hawkmoth. J. Comp. Physiol. A. 192, 431-437.

Bartholomew, G. A., and Casey, T. M. (1978). Oxygen consumption of moths during rest, pre-flight warm-up, and flight in relation to body size and wing morphology. J. Exp. Biol. 76, 11-25.

Berg, B. G., Almaas, T. J., Bjaalie, J. G., and Mustaparta, H. (1998). The macroglomerular complex of the antennal lobe in the tobacco budworm moth Heliothis virescens: specified subdivision in four compartments according to information about biologically significant compounds. J. Comp. Physiol. A. 183, 669-682.

Berg, B. G., Almaas, T. J., Bjaalie, J. G., and Mustaparta, H. (2005). Projections of male-specific receptor neurons in the antennal lobe of the oriental tobacco budworm moth, Helicoverpa assulta: a unique glomerular organization among related species. J. Comp. Neurol. 486, 209-220.

Berg, B. G., Tumlinson, J. H., and Mustaparta, H. (1995). Chemical communication in heliothine moths IV. Receptor neuron responses to pheromone compounds and formate analogs in the male tobacco budworm moth Heliothis virescens. J. Comp. Physiol. A. 177, 527-534.

Biederlack, J., Castelo-Branco, M., Neuenschwander, S., Wheeler, D. W., Singer, W., and Nikolic, D. (2006). Brightness induction: rate enhancement and neuronal synchronization as complementary codes. Neuron 52 , 1073-1083.

Byers, J. A. (2005). Chemical constraints on the evolution of olfactory communication channels of moths. J. Theor. Biol. 235, 199-206.

Byers, J.A. (2006). Pheromone component patterns of moth evolution revealed by computer analysis of the Pherolist. J. Anim. Ecol. 75, 399-407.

Carde, R. T., Roelofs, W. L., Harrison, R. G., Vawter, A. T., Brussard, P. F., Mutuura, A., and Munroe, E. (1978) European corn borer-pheromone polymorphism or sibling species? Science 199, 555-556.

Carlsson, M. A., Galizia, C. G., and Hansson, B. S. (2002). Spatial representation of odours in the antennal lobe of the moth Spodoptera littoralis (Lepidoptera: Noctuidae). Chem. Senses. 27, 231-244.

Chittka, L., Thomson, J. D., and Waser, N. M. (1999). Flower constancy, insect psychology, and plant evolution. Naturwissenschaften 86 361-377.

Christensen, T. A., Harrow, I. D. Cuzzocrea, C., Randolph, P. W., and Hildebrand, J. G. (1995a). Distinct projections of 2 populations of olfactory receptor axons in the antennal lobe of the sphinx moth Manduca sexta. Chem. Senses 20, 313-323.

Christensen, T. A., Mustaparta, H., and Hildebrand, J. G. (1995b). Chemical communication in heliothine moths VI. Parallel pathways for information processing in the macroglomerular complex of the male tobacco budworm moth Heliothis virescens. J. Comp. Physiol. A. 177, 545-557.

Christensen, T. A., and Hildebrand, J. G. (1987). Male-specific, sex pheromone-selective projection neurons in the antennal lobes of the moth Manduca sexta. J. Comp. Physiol. A. $160,553-569$.

Christensen, T. A., and Hildebrand, J. G (1997). Coincident stimulation with pheromone components improves temporal pattern resolution in central olfactory neurons. J. Neurophysiol. 77 775-781.

Christensen, T. A., and Hildebrand, J. G. (2002). Pheromonal and host-odor processing in the insect antennal lobe: how different? Curr. Opin. Neurobiol. 12, 393-399.

Christensen, T.A., Waldrop, B. R., Harrow I. D., and Hildebrand, J. G. (1993). Local interneurons and information processing in the olfactory glomerul of the moth Manduca sexta. J. Comp. Physiol. A. 173, 385-399.

Chou, Y. H., Spletter, M. L., Yaksi, E., Leong, J. C., Wilson, R. I., and Luo L. (2010). Diversity and wiring variability of olfactory local interneurons in the Drosophila antennal lobe. Nat. Neurosci. 13, 439-449.

Cleland, T. A., Johnson, B. A., Leon, M., and Linster, C. (2007). Relational representation in the olfactory system. Proc. Natl. Acad. Sci. U.S.A. 104 1953-1958.

Cunningham, J. P., Moore, C. J., Zalucki, M. P., and West, S. A. (2004) Learning, odour preference and flower foraging in moths. J. Exp. Biol. 207, 87-94.

Daly, K. C., Christensen, T. A., Lei, H. Smith, B. H., and Hildebrand, J. G. (2004). Learning modulates the ensemble representations for odors in primary olfactory networks. Proc. Natl. Acad. Sci. U.S.A. 101 10476-10481.

Daly, K. C., and Smith, B. H. (2000). Associative olfactory learning in the moth Manduca sexta. J. Exp. Biol. 203 , 2025-2038.

Dan, Y., Alonso, J. M., Usrey, W. M., and Reid, R. C. (1998). Coding of visua information by precisely correlated spikes in the lateral geniculate nucleus. Nat. Neur. 1, 501-507.

Darwin, C. (1862). On the Various Contrivances by Which British and Foreign Orchids are Fertilised by Insects and on the Good Effects of Intercrossing 1st Edn. London: John Murray.

Davis, R. L. (2004). Olfactory learning. Neuron 44, 31-48.

Domingue, M. J., Haynes, K. F., Todd, J. L. and Baker, T. C. (2009). Altered olfactory receptor neuron responsiveness is correlated with a shift in behavioral response in an evolved colony of the cabbage looper moth, Trichoplusia ni. J. Chem. Ecol. 35, 405-415.

Domingue, M. J., Musto, C. J., Linn, C. E., Roelofs, W.L., and Baker, T.C. (2007a). Altered olfactory receptor neuron responsiveness in rare Ostrinia nubilalis males attracted to the $O$. furnacalis pheromone blend. J. Insect Physiol. 53, 1063-1071.
Domingue, M. J., Musto, C. J., Linn, C. E., Roelofs, W. L., and Baker, T. C. (2007b). Evidence of olfactory antagonistic imposition as a facilitator of evolutionary shifts in pheromone blend usage in Ostrinia spp. (Lepidoptera: Crambidae). J. Insect Physiol. 53, 488-496.

Domingue, M. J., Musto, C. J., Linn, C. E., Roelofs, W. L., and Baker, T. C. (2008). Olfactory neuron responsiveness and pheromone blend preference in hybrids between Ostrinia furnacalis and Ostrinia nubilalis (Lepidoptera Crambidae). J. Insect Physiol. 54, 1261-1270.

Dusenberry, D. B. (1992). Sensory Ecology: How Organisms Acquire and Respond to Information? New York: Freeman.

Engel, A. K., Konig, P., and Singer, W. (1992). Temporal coding in the visual system-synchrony as a glue for cortical cell assemblies. Eur. J. Neurosci. S5, 218-226.

Engel, A. K., and Singer, W. (2001). Temporal binding and the neural correlates of sensory awareness. Trends Cogn. Sci. 5, 16-25.

Fan, R. J., Anderson, P., and Hansson, B. S. (1997). Behavioural analysis of olfactory conditioning in the moth Spodoptera littoralis (Boisd.) (Lepidoptera: Noctuidae).J. Exp. Biol. 200, 2969-2976.

Galizia, C. G., Sachse, S., and Mustaparta, H. (2000). Calcium responses to pheromones and plant odours in the antennal lobe of the male and female moth Heliothis virescens. J. Comp. Physiol. A. 186, 1049-1063.

Ghose, G. M., Ohzawa, I., and Freeman, R. D. (1994). Receptive field maps of correlated discharge between pairs of neurons in the cats visual cortex. $J$ Neurophysiol. 71, 330-346.

Grant, A. J., Mayer, M. S., and Mankin, R. W. (1989). Responses from sensilla on antennae of male Heliothis $z e a$ to its major pheromone component and 2 analogs. J. Chem. Ecol. 15, 2625-2634

Grant, V., and Grant, K. A. (1983). Hawkmoth pollination of Mirabilis longiflora (Nyctaginaceae). Proc. Natl. Acad. Sci. U.S.A. 80, 1298-1299.

Grosse-Wilde, E., Svatos, A., and Krieger, J. (2006). A pheromone-binding protein mediates the bombykol-induced activation of a pheromone receptor in vitro. Chem. Senses 31, 547-555.

Hallem, E. A., and Carlson, J. R. (2006). Coding of odors by a receptor repertoire. Cell 125, 143-160.

Hansson, B. S., Carlsson, M. A., and Kalinovà, B. (2003). Olfactory activation patterns in the antennal lobe of the sphinx moth, Manduca sexta. J. Comp. Physiol. A. 189, 301-308. 
Hansson, B. S., Christensen, T. A., and Hildebrand, J. G. (1991). Functionally distinct subdivisions of the macroglomerular complex in the antennal lobe of the male sphinx moth Manduca sexta. J. Comp. Neurol. 312, 264-278.

Hartlieb, E. (1996). Olfactory conditioning in the moth Heliothis virescens. Naturwissenschaften 83, 87-88.

Haynes, K. F., and Hunt, R. E. (1990). Interpopulational variation in emitted pheromone blend of cabbage looper moth, Trichoplusia ni. J. Chem. Ecol. $16,509-519$.

Hildebrand, J. G., and Shepherd, G. M. (1997). Mechanisms of olfactory discrimination: converging evidence for common principles across phyla. Annu. Rev. Neurosci. 20, 595-631.

Hoskins, S. G., Homberg, U., Kingan, T. G., Christensen, T.A., and Hildebrand, J. G. (1986). Immunocytochemistry of gaba in the antennal lobes of the sphinx moth Manduca sexta. Cell Tissue Res. 244, 243-252.

Kaissling, K. E., Hildebrand, J. G., and Tumlinson, J. H. (1989). Pheromone receptor cells in the male moth Manduca sexta. Arch. Insect Biochem. Physiol. 10, 273-279.

Karpati, Z., Dekker, T., and Hansson, B. S. (2008). Reversed functional topology in the antennal lobe of the male European corn borer. J. Exp. Biol. 211, 2841-2848.

Kazama, H., and Wilson, R. I. (2009). Origins of correlated activity in an olfactory circuit. Nat. Neurosci. 12, 1136-1144.

Krahe, R., Kreiman, G., Gabbiani, F., Koch, C., and Metzner, W. (2002). Stimulus encoding and feature extraction by multiple sensory neurons. J. Neurosci. 22, 2374-2382.

Lee, S. G., Carlsson, M. A., Hansson, B. S., Todd, J. L., and Baker, T. C. (2006a). Antennal lobe projection destinations of Helicoverpa zea male olfactory receptor neurons responsive to heliothine sex pheromone components. J. Comp. Physiol. A. 192, 351-363.

Lee, S. G., Vickers, N. J., and Baker, T. C. (2006b). Glomerular targets of Heliothis subflexa male olfactory receptor neurons housed within long trichoid sensilla. Chem. Senses 31, 821-834.

Lei, H., Christensen, T.A., and Hildebrand, J. G. (2002). Local inhibition modulates odor-evoked synchronization of glomerulus-specific output neurons. Nat. Neurosci. 5, 557-565.

Lei, H., Christensen, T.A., and Hildebrand, J. G. (2004). Spatial and temporal organization of ensemble representations for different odor classes in the moth antennal lobe. J. Neurosci. 24, 11108-11119.

Lestienne, R. (2001). Spike timing, synchronization and information processing on the sensory side of the central nervous system. Prog. Neurobiol. 65, 545-591.

Linn, C., Jr., O'Connor, M., and Roelofs, W. (2003). Silent genes and rare males: a fresh look at pheromone blend response specificity in the European corn borer moth, Ostrinia nubilalis. J. Insect Sci. 3, 15.

Linster, C., Sachse, S., and Galizia, C. G. (2005). Computational modeling suggests that response properties rather than spatial position determine connectivity between olfactory glomeruli. J. Neurophysiol. 93, 3410-3417.

Liu, Y. B., and Haynes, K. F. (1994). Evolution of behavioral responses to sex pheromone in mutant laboratory colonies of Trichoplusia ni. J. Chem. Ecol. 20, 231-238.

Lofstedt, C. (1990). Population variation and genetic control of pheromone communication systems in moths. Entomol. Exp. Appl. 54, 199-218.

Marsat, G., Proville, R. D., and Maler, L. (2009). Transient signals trigger synchronous bursts in an identified population of neurons. J. Neurophysiol. 102, 714-723.

Matsumoto, S. G., and Hildebrand, J. G. (1981). Olfactory mechanisms in the moth Manduca sexta-response characteristics and morphology of central neurons in the antennal lobes. Proc. $R$. Soc. London, Ser. B. 213, 249-277.

Meister, M. (1996). Multineuronal codes in retinal signaling. Proc. Natl. Acad. Sci. U.S.A. 93, 609-614.

Memmott, J., Waser, N. M., and Price, M. V. (2004). Tolerance of pollination networks to species extinctions. Proc. R. Soc. London, Ser. B. 271, 2605-2611.

Nilsson, L. A. (1988). The evolution of flowers with deep corolla tubes. Nature 334, 147-149.

Perkel, D. H., Gerstein, G. L., and Moore, G. P. (1967). Neuronal spike trains and stochastic point processes. II. Simultaneous spike trains. Biophys. J. 7, 419-440.

Pinero, J. C., Galizia, C. G., and Dorn, S. (2008). Synergistic behavioral responses of female oriental fruit moths (Lepidoptera: Tortricidae) to synthetic host plant-derived mixtures are mirrored by odor-evoked calcium activity in their antennal lobes. J. Insect Physiol. 54, 333-343.

Plepys, D., Ibarra, F., Francke, W., and Lofstedt, C. (2002). Odour-mediated nectar foraging in the silver Y moth, Autographa gamma (Lepidoptera: Noctuidae): behavioural and elec- trophysiological responses to floral volatiles. Oikos 99, 75-82.

Raguso, R. A., Henzel, C., Buchmann, S. L., and Nabhan, G.P. (2003). Trumpet flowers of the Sonoran Desert: floral biology of Peniocereus cacti and sacred Datura. Int. J. Plant Sci. 164, 877-892.

Raguso, R. A., and Willis, M. A. (2002). Synergy between visual and olfactory cues in nectar feeding by naive hawkmoths, Manduca sexta. Anim. Behav. 64, 685-695.

Reinhard, J., Sinclair, M., Srinivasan, M.V. and Claudianos, C. (2010). Honeybees learn odour mixtures via a selection of key odorants. PLoS One 5, e9110. doi:10.1371/journal.pone.0009110.

Reisenman, C. E., Heinbockel, T., and Hildebrand, J. G. (2008). Inhibitory interactions among olfactory glomeruli do not necessarily reflect spatial proximity. J. Neurophysiol. 100, 554-564.

Riffell, J. A., Alarcon, R., Abrell, L., Davidowitz, G., Bronstein, J. L., and Hildebrand, J. G. (2008). Behavioral consequences of innate preferences and olfactory learning in hawkmothflower interactions. Proc. Natl. Acad. Sci. U.S.A. 105, 3404-3409.

Riffell, J. A., Lei, H., Christensen, T. A., and Hildebrand, J. G. (2009a). Characterization and coding of behaviorally significant odor mixtures. Curr. Biol. 19, 335-340.

Riffell, J. A., Lei, H., and Hildebrand, J. G. (2009b). Inaugural article: neural correlates of behavior in the moth Manduca sexta in response to complex odors. Proc. Natl. Acad. Sci. U.S.A. 106 19219-19226.

Robertson, L. C. (2003). Binding, spatial attention and perceptual awareness. Nat. Rev. Neurosci. 4, 93-102.

Sachse, S., and Galizia, C. G. (2002). Role of inhibition for temporal and spatial odor representation in olfactory output neurons: a calcium imaging study. J. Neurophysiol. 87, 1106-1117.

Sachse, S., and Galizia, C. G. (2003). The coding of odour-intensity in the honeybee antennal lobe: local computation optimizes odour representation. Eur. J. Neurosci. 18, 2119-2132.

Silbering, A. F., and Galizia, C. G. (2007). Processing of odor mixtures in the Drosophila antennal lobe reveals both global inhibition and glomerulusspecific interactions. J. Neurosci. 27, 11966-11977.

Singer, W. (1999). Neuronal synchrony: a versatile code for the definition of relations? Neuron 24, 49-65.

Skiri, H. T., Galizia, C. G., and Mustaparta, H. (2004). Representation of primary plant odorants in the antennal lobe of the moth Heliothis virescens using calcium imaging. Chem. Senses 29 253-267.

Touhara, K., and Vosshall, L. B. (2009). Sensing odorants and pheromones with chemosensory receptors. Annu. Rev. Physiol. 71, 307-332.

Tumlinson, J. H., Brennan, M. M., Doolittle, R. E., Mitchell, E. R., Brabham, A., Mazomenos, B. E., Baumhover, A. H., and Jackson, D. M. (1989). Identification of a pheromone blend attractive to Manduca sexta (L) males in a wind-tunnel. Arch. Insect Biochem. Physiol. 10, 255-271.

Uchida, N., and Mainen, Z. F. (2007). Odor concentration invariance by chemical ratio coding. Front. Syst. Neurosci. 1, 3. doi: 10.3389/ neuro.06.003.2007.

Vickers, N. J., and Christensen, T. A. (1998).A combinatorial model of odor discrimination using a small array of contiguous, chemically defined glomeruli in Olfaction and Taste XII-An International Symposium, ed. C. Murphy. Ann. N.Y. Acad. Sci. 855, 514-516.

Vickers, N. J., and Christensen, T. A. (2003). Functional divergence of spatially conserved olfactory glomeruli in two related moth species. Chem. Senses 28, 325-338.

Vickers, N. J., Christensen, T. A., and Hildebrand, J. G. (1998). Combinatorial odor discrimination in the brain: attractive and antagonist odor blends are represented in distinct combinations of uniquely identifable glomeruli. J. Comp. Neurol. 400, 35-56.

Waldrop, B., Christensen, T. A., and Hildebrand, J. G. (1987). Gabamediated synaptic inhibition of projection neurons in the antennal lobes of the sphinx moth, Manduca sexta. J. Comp. Physiol. A. 161, 23-32.

Wall, C., and Perry, J. N. (1987). Range of action of moth sex-attractant sources. Entomol. Exp. Appl. 44, 5-14.

Wang, J. W., Wong, A. M., Flores, J., Vosshall, L. B., and Axel, R. (2003). Two-photon calcium imaging reveals an odor-evoked map of activity in the fly brain. Cell 112, 271-282.

Wanner, K. W., Nichols, A. S., Allen, J. E., Bunger, P. L., Garczynski, S. F., Linn, C. E., Robertson, H. M., and Luetje, C. W. (2010). Sex pheromone receptor specificity in the European corn borer moth, Ostrinia nubilalis. PLoS One 5, e8685. doi:10.1371/journal. pone.0008685.

Waser, N. M., Chittka, L., Price, M. V., Williams, N. M., and Ollerton, J. (1996). Generalization in pollination systems, and why it matters. Ecology 77, 1043-1060. 
Wilson, R. I., and Laurent, G. (2005). Role of GABAergic inhibition in shaping odor-evoked spatiotemporal patterns in the Drosophila antennal lobe. J. Neurosci. 25, 9069-9079.

Wilson, R. I., and Mainen, Z. F. (2006). Early events in olfactory processing. Annu. Rev. Neurosci. 29, 163-201.
Conflict of Interest Statement: The authors declare that the research was conducted in the absence of any commercial or financial relationships that could be construed as a potential conflict of interest.

Received: 24 March 2010; paper pending published: 13 July 2010; accepted:
9 August 2010; published online: 24 September 2010.

Citation: Martin JP and Hildebrand JG (2010) Innate recognition of pheromone and food odors in moths: a common mechanism in the antennal lobe?. Front Behav. Neurosci. 4:159. doi: 10.3389/ fnbeh.2010.00159
Copyright (c) 2010 Martin and Hildebrand. This is an open-access article subject to an exclusive license agreement between the authors and the Frontiers Research Foundation, which permits unrestricted use, distribution, and reproduction in any medium, provided the original authors and source are credited. 